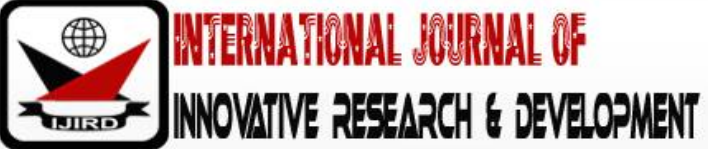

ISSN 2278 - 0211 (Online)

\section{Chemistry Students' Cognitive Operations and Achievement in Conceptual and Computational Knowledge in Inquiry-based Instructions}

\author{
Dr. Ikeoluwa Folasade Adeoye \\ Lecturer, Department of Science Education, Lead City University, Ibadan, Oyo State, Nigeria
}

\begin{abstract}
The study investigated chemistry students' cognitive operational level and the impact of inquiry-based instructions on students' cognitive operational level on conceptual and computational knowledge in chemistry. The samples were three hundred and fifty-nine (359) senior secondary school students randomly sampled from nine secondary schools. The schools were assigned to Teacher Demonstration (TD), Investigate-Discuss (ID) and Predict-Discuss-Investigate-Discuss (PDID) instructional modes. The study adopted quasi experimental design of pre-test post-test control group. The research instruments were Logical Thinking Test (LTT), Conceptual Knowledge Test and Computational Knowledge Test (CKT). The instruments were validated and their reliability determined with positive internal consistency. These instruments pre-administered and post-administered after eight weeks of active engagement in learning. Simple percentage and mean statistical methods employed in the data analysis. The findings showed that 355 sampled students were at the concrete operational level, 3 students were in transitional level while 1 student was in formal operational level before treatment. The inquiry-based instructions enhanced student logical reasoning with 192 students operated at concrete level, 130 students were at transitional level and 37 students were at formal operational level after treatment. Also, the students' level of cognitive operation influenced their achievement in conceptual and computational knowledge as students in formal operational level achieved highest in both conceptual and computational knowledge. The implications of the findings and recommendations were discussed.
\end{abstract}

Keywords: Inquiry-based instructions, conceptual knowledge, computational knowledge, logical thinking, concrete operational level, transition operational level, formal operational level

\section{Introduction}

Chemistry is a highly conceptual subject with high abstract of ideas that requires high cognitive thinking to meaningfully grasp and understanding its concepts (Taber, 2019). Chemistry students need to attain formal operational level of Piaget's intellectual development to be able to formulate hypotheses and to systematically test the hypotheses to arrive at the valid answer. The formal operational stage is usually from 12 years to adulthood. At this period of formal operations, the child's thought processes are logical, well-integrated and in abstraction. The students at formal operational stage understand and transfer their understanding from one situation to another in solving problems. They show the ability to systematically solve a problem in a logical and methodological way (Piaget, 1983 and Santrock, 2008).

Piaget identified four stages of intellectual development as sensorimotor, pre-operational, concrete operational and formal operational stages. Each of these stages correlates with age and thinking abilities. Piaget's intellectual growth or cognitive development is a complex process comprising of three principal concepts that affect the developmental process namely: assimilation, accommodation and equilibration. The process of assimilation in Piaget theory, involves the incorporation of new information into pre-existing cognition. Accommodation means changing the existing structures in order to fit in new information while equilibration involves the learner striking a balance between him and the environment (information). When a child experiences a new event, disequilibrium and perturbation of cognitive structure set in until the child is able to assimilate and accommodate the new information and thus attains equilibrium.

According to Piaget, equilibration is the major factor why some children advance more quickly in the development of logical reasoning than do others. All the three are associated with the formation of schemata (cognitive structure) and their modification in order to attain a balanced sense of understanding of the external world. Each operational stage has major cognitive characteristics. The sensorimotor stage (birth-2 years) is characterised by rudimentary perceptual abilities, reflexive movements, inability to mentally represent unseen objects, non-random movements in responses to sensations. The cognitive features of the pre-operational stage (2-7 years) are representational thought, egocentric thinking, inability to solve conservational problems and difficulty with transitive relationships. For the concrete operational stage (7-12 years), this is characterized by mastery of the conservation concepts, ability to perform operations on concrete ideas and objects. Mental operations on abstract or hypothetical elements and understanding 
relationships among relationships are difficult for the children at this stage. Formal operational stage (12 years to adulthood) individual is able to perform all the cognitive abilities described in all the previous stages and they can reason in abstraction, accumulate knowledge and skills with the mastery of thought.

In chemistry, much of what is learnt requires formal reasoning that is based on abstraction which transcends concrete experiences (Gilbert and Treagust, 2009, Adesoji and Omilani, 2012 and Adeoye, 2019). Students' poor performance in chemistry examinations may be attributed to students' poor development of formal operational thought. Piaget and Inhelder (1969), Oloyede (2012), Bello (2014) and Piraksa, Srisawasdi and Koul (2014) had discovered that many students find abstract subjects such as chemistry and physics difficult to learn due to the students' levels of intellectual development. As a result, most science students are not able to apply knowledge acquired in the class environment to everyday life.

Several studies have been undertaken to determine the relationship between logical reasoning ability and students' performance in science but little researches exist in the effects of logical reasoning on students' conceptual and computational achievement in chemistry. Kamaruddin, Abubakar, Surif and Siew (2008) identified and showed relationships of Form Four Malaysian science students' cognitive styles, level of cognitive thinking and the chemistry achievement. The results showed that most (68\%) of the students were at the concrete level of cognitive thinking and the students' achievement in chemistry was low. The findings also showed weak relationship between the students' cognitive styles, the level of cognitive thinking and achievement in chemistry. There were no significant relationships among the variables. This means that achievement in chemistry was not very much influenced by students' cognitive styles and the levels of cognitive thinking.

Lay (2010) investigated the acquisition of logical thinking abilities among rural secondary school students of Sabah, Malaysia. The study found that up to $98 \%$ of the respondents were categorised at concrete operational stage whereas only $2 \%$ was categorised at operating in the transitional stage. There was no significant difference in the mean of logical thinking abilities based on students' gender but a significant difference existed based on students' science achievement. Furthermore, Kincal and Yazgan (2010) examined the formal operational thinking skills of students in high school students in Turkey. They showed that $60.9 \%$ of the students were operating at the concrete level while $15.1 \%$ of them were at the formal operational level. Also, there was no significant difference found between the students' logical thinking by gender but there were significant differences between the students' logical thinking on type of school (private and public), academic success, socio-economic background and socio-cultural background.

Kilic and Sagam (2014) examined the predictive influence of reasoning ability and learning orientations. The study revealed cognitive variables investigated accounted for $27 \%$ statistical significant variance in the students' understanding of genetic concepts. The study also showed that reasoning ability and meaningful learning predicted students' understanding of genetics concepts in positive direction while rote learning predicted students understanding of genetic concepts in negative direction. Bhat (2016) also examined the predictive ability of six components of reasoning ability of inductive, deductive, linear, conditional, cause-and-effect and analogical reasoning in academic achievement of tenth students. The result indicated that predictive power of the components of reasoning ability accounted for $31.5 \%$ for academic achievement. The maximum power was 0.49 for deductive reasoning followed by cause and effect reasoning with 0.26 while inductive, linear, conditional and analogical reasoning had very low values of predictive power.

Bird (2010) identified gender effects and determined reasoning modes that were best predictors of students' performance in a college general chemistry course in Rio Piedras. Nineteen percent (19\%) of the students were at the concrete level, $40 \%$ were at the transitional stage and $41 \%$ had reached the formal operational level. This means that, even at the university level, $59 \%$ of the students who enrolled in the general chemistry course did not reach the formal operational stage. The students' logical reasoning ability was a predictor of students' performance in the course. Out of the six logical reasoning modes examined in this study, most students showed marked deficiencies in proportional, probabilistic and correlational reasoning and probabilistic reasoning was the single best predictor of the students' performance. The students' responses to the items in the chemistry test varied significantly with the students' operational level, with formal thinkers having a stronger tendency to apply the conceptual approach and the students at the formal operational level performed significantly better in the general chemistry examination than the students operating at lower levels. These findings imply that logical reasoning skills are essential for student's mastery of many concepts and more complex problem-solving strategies are required for success in general chemistry. Nnorom (2013) indicated that the students with high reasoning ability achieved better in biology than those students with low reasoning ability in science. Khoirina, Cari and Sukarmin (2018) found that $51.14 \%$ of the physics students in Surakarta, Indonesia were at concrete operational level of reasoning, $42.05 \%$ were at transitional level and $6.81 \%$ were at the formal reasoning level.

Ertepmar (1995) and Oloyede (2012) found that formal reasoning ability is strong predictor for academic achievement in chemistry. Oloyede investigated the relationship between Nigerian Secondary School form one students' acquisition of science process skills, formal reasoning ability (using the six modes) and achievement in chemistry. The results showed positive relationships between formal reasoning ability and acquisition of process skills, formal reasoning and chemistry achievement and acquisition of science process skills and achievement.

Piraksa et al. (2014) examined the effect of gender on students' scientific reasoning in the six constructs of conservation of mass and volume, proportional thinking, controlling variables, probabilistic thinking, correlational thinking and hypothetic-deductive thinking. The result showed that gender did not significantly influence students' science reasoning. Mari (2012) investigated gender related differences in acquisition of formal reasoning using process-based approaches. The study showed that process-based approaches enhanced students' formal reasoning in chemistry and recommended that he should be used to reduce gender related in reasoning ability between male and female students in secondary schools. Yuksel (2019) also showed no significant difference in between the achievement of male and female of 
prospective science teachers in logical reasoning. Reasoning ability of students is measured by the level of their performance on the constructs of conservation of mass and volume, proportional thinking, control of variables probabilistic thinking, correlational thinking and hypothetical-deductive reasoning.

The performance of students in science was reported to be poor and persistent according to Adeoye (2016), Ngema (2016) and Anthony, Shabban and Nassor (2019). Among other factors identified for students' poor performance in chemistry are teachers' poor qualifications, poor method of teaching time allocated for science teaching, lack of adequate content knowledge, approach to instruction and lack of educational resources (Ojukwu, 2016 and Adeoye and Agoro, 2019). For students to achieve adequately in chemistry, their reasoning ability must transient that of the observable phenomena to abstract reasoning of the scientific concept (Johnstone, 1991 and Adeoye and Ajeyalemi, 2018). Achievement in chemistry is majorly based on students' ability to solve quantitative and qualitative problems. The qualitative aspect of problem solving is the conceptual knowledge while the quantitative aspect of problem solving is computational knowledge that students have in the subject. Conceptual knowledge is the understanding of the fundamental concepts in chemistry. It is the integration of knowledge among concepts which may involve the representation at the three levels of symbolic, microscopic and macroscopic representations (Adesoji and Omilani, 2012 and Adeoye and Ajeyalemi, 2016). Adeoye (2019) reported that adequate knowledge of conceptual knowledge is needed for students to effectively solve quantitative problems in chemistry hence students would resolve into the use of algorithms in solving quantitative problems. Gabel and Bunce (1994) and Holme, Luxford and Brandriet (2015) reported that one the major reasons that students make problem-solving difficult for students was that they lack the understanding of basic concepts in chemistry. This calls for in depth core chemistry ideas that go beyond mere rote memorization and the using of algorithmic problem solving. Critical thinking is necessary in not only in problem solving but in translating across the three domains of representations in chemistry.

Inquiry-based learning is one of the teaching strategies recommended in Nigerian science curricula to promote critical reasoning and conceptual understanding. Inquiry-based learning can take many approaches depending on the way it is structured by the teachers. There many researches on students reasoning and inquiry-based learning but few are available in science. The available researches had not related students' logical thinking to their achievement in conceptual and computational knowledge and logical thinking levels of the students to inquiry- based learning especially in chemistry. Hence, this study investigated the level at which most Nigeria chemistry students are operating and effect on students' conceptual and computational knowledge. The effect of inquiry-based approaches on students' levels of cognitive operation and achievement in conceptual and computational knowledge. However, the significant effect of the inquirybased approaches was not determined in the study.

\section{Research Question}

The research questions are as follows:

- What is the effect of inquiry-based instructions on students' logical thinking in chemistry?

- Which level of cognitive operations are most senior secondary school students operating in chemistry?

- How do the students' levels of cognitive operations influence the achievement in conceptual and computational knowledge in inquiry-based instructions?

\section{Methodology}

Achievement of students in conceptual and computational knowledge in chemistry based on their cognitive operations was examined using quasi experimental research design of pretest posttest in three inquiry modes of learning. The inquiry instructions were Teacher Demonstration (TD), Investigate Discuss (ID) and Predict-Discuss-InvestigateDiscuss (PDID). The inquiry instructions were characterised by activities and problem-solving but implementation modes were different. The learning packages for the three modes had the same contents of chemistry in redox reactions, electrolysis, kinetics and chemical equilibria. The TD was basically a teacher-centered where the teacher performed and discussed the principles underlying the experiments the teacher carried out. The teacher also discussed and solved related problems the experiments. The ID and PDID inquiry instructions were student-centered. The activities that were involved in the experiments were carried out by the students in groups of five to six members. The students discussed the underlying principles and solved the related problems within their small learning groups. The major difference between the two modes of instructions was that in the PDID students made intelligent guesses which were later refuted, accepted or modified after the experiments and discussions while in the ID, the students carried out the experiment without making any prediction.

Nine senior secondary schools were randomly sampled and the schools randomly assigned to the three modes of instruction. The total number of the sampled students was three hundred and fifty-nine (359). Three research instruments namely Logical Thinking Test (LTT), Conceptual Knowledge Test (CKT) and Computational Ability Test (CAT) were used to collect data from the subjects. The instruments were validated and the reliability of LTT, CKT and CAT were determined using Spearman rank and Kuder-Richardson KR20 correlation. The reliability of the co-efficient value was 0.85 for CKT, 0.73 for CAT while LTT had 0.78. The LTT, CKT and CAT were administered to the subjects two days before treatment and three days after eight weeks of treatment. Four chemistry topics; chemical equilibrium, redox reactions, chemical kinetics and electrolysis were treated and examined. The CKT had eight major questions and each question had three subquestions while CAT contained eight questions without any sub- questions. The CKT evaluated students deep and meaningful understanding of the chemistry concepts while the CAT was the quantitative problems related to the CKT. Twenty items were contained in the LTT to examined formal reasoning ability of the subjects. The format of Lawson (2009) and Oloyede (2012) on logical reasoning was adapted. The items were structured on five constructs of correlation, 
proportionality, identifying and controlling of variables, probability and hypothetic - deductive thinking. The subjects were categorised into three operational levels based on their scores in LTT. Subjects that had scores between 0 - $45 \%$ were classified as concrete operational level, 46 - $69 \%$ were in transitional level and 70 - above \% as formal operational level. Examples of logical thinking questions are:

It can be concluded from this statement above that

- The same quantity of electricity was passed through the two electrolytes.

- The number of moles of silver deposited is the same with that of copper deposited.

- The charge on the copper ion is +2 while that on the silver is +1 .

- The numbers of moles of copper and silver charges are inversely proportional to the charges on their ions when the same quantity of electricity is passed.

If the temperature of the system is increased, what would be the possible effect on equilibrium reaction?

- Backward reaction would be favoured

- Forward reaction would be favoured

- Reaction would stop

- Reaction would be at equilibrium.

The researcher trained at least two chemistry teachers in the schools were subjects were sampled. The training was on the assigned learning packages designed to reflect the inquiry-based approaches. The teachers with high proficiency in the implementation of the learning packages were chosen for the treatment.

The scores of the subjects in the CKT, CAT and LTT were collated and analysed employing simple percentage, mean and standard deviation.

\section{Result}

\begin{tabular}{|c|c|c|c|c|c|c|}
\hline Treatment & $\begin{array}{c}\text { Number of } \\
\text { Student }\end{array}$ & $\begin{array}{c}\text { Post-LTT } \\
\text { Mean Score }\end{array}$ & $\begin{array}{c}\text { Standard } \\
\text { Deviation }\end{array}$ & $\begin{array}{c}\text { Pre-LTT } \\
\text { Mean Score }\end{array}$ & $\begin{array}{c}\text { Standard } \\
\text { Deviation }\end{array}$ & $\begin{array}{c}\text { Mean } \\
\text { Gain }\end{array}$ \\
\hline TD & 122 & 42.09 & 11.48 & 28.28 & 12.63 & 13.81 \\
\hline ID & 114 & 46.54 & 12.57 & 28.77 & 9.77 & 17.77 \\
\hline PDID & 123 & 54.11 & 10.96 & 32.36 & 11.04 & 21.75 \\
\hline
\end{tabular}

Table 1: Pretest and Posttest Mean Scores on Logical Thinking Test by Treatment

\begin{tabular}{|c|c|c|c|c|}
\hline Test & $\begin{array}{c}\text { Logical Thinking } \\
\text { Level }\end{array}$ & Number of Student & $\begin{array}{c}\text { Mean Achievement } \\
\text { CKT }\end{array}$ & $\begin{array}{c}\text { Mean Achievement } \\
\text { CAT }\end{array}$ \\
\hline \multirow{3}{*}{ Pre } & Concrete & $355(98.88 \%)$ & 26.56 & 10.29 \\
& Transition & $3(0.84 \%)$ & 29.00 & 17.50 \\
& Formal & $1(0.28 \%)$ & 32.00 & 21.00 \\
\hline \multirow{3}{*}{ Post } & Concrete & $192(53.48 \%)$ & 35.02 & 21.13 \\
& Transition & $130(36.21 \%)$ & 43.63 & 24.54 \\
& Formal & $37(10.31 \%)$ & 51.35 & 26.49 \\
\hline
\end{tabular}

Table 2: Levels of Logical Thinking and Achievement in Conceptual and Computational Knowledge Source: Adeoye (2016)

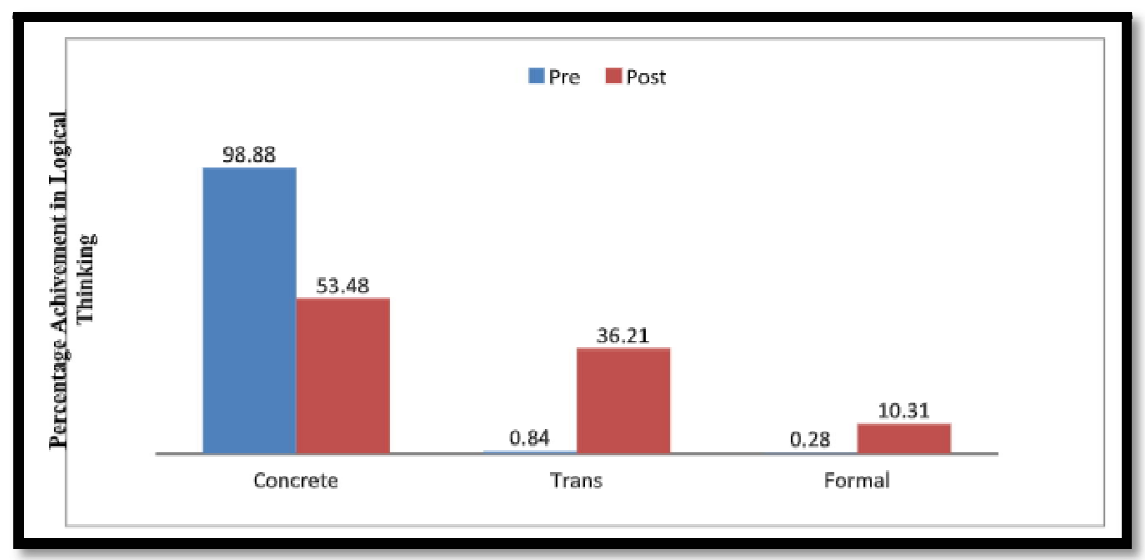

Figure 1: Levels of Students' Cognitive Operations 


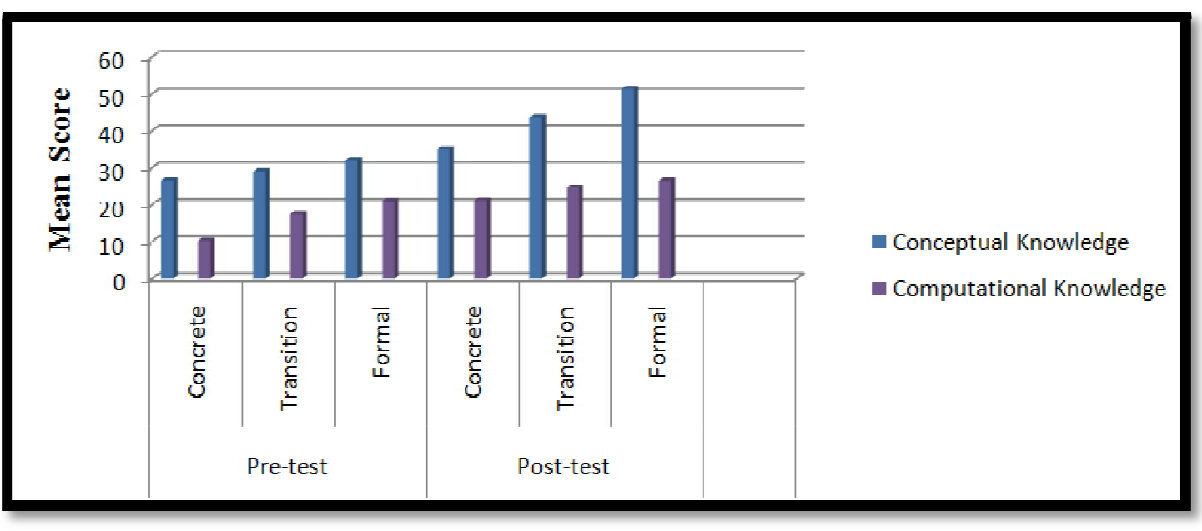

Figure 2: Achievement in Conceptual and Computational Knowledge Based on Cognitive Operations

\section{Discussion of Findings}

The inquiry-based instructions benefited the students in their chemistry reasoning ability. This was shown in the students' achievement in the Logical Ability Test in Chemistry. The results presented on Table 1 indicated that the students in TD had mean gain score of 13.81, their counterparts in the ID group had 17.77 while those in the PDID group had mean gain of 21.75.These implied that the students in the PDID achieved highest, followed by those in the ID and then those in the TD. The PDID learning strategy had more positive impact on the students' logical reasoning than those in the ID and TD.

The results presented on Table 2 show that at the pre-test level, only one (1) student was at the formal operational stage and three (3) of the sampled subjects were at transition operational level while three hundred and fiftyfive (355) students were at concrete operational stage. Majority of the sampled students had not attained to the formal reasoning level in Chemistry. The achievements of students at pre-test and post-test in conceptual knowledge and computational knowledge were influenced by the level of students' cognitive operations in Chemistry. The findings were in support with Oloyede (2012) who found that majority of Senior Secondary School Chemistry were in concrete operational level. He also showed that students' conceptual understanding but not in computational knowledge was influenced by the students' cognitive operational level. The achievement scores of students at concrete, transition and formal operational levels in conceptual knowledge were 26.56, 29.00 and 32.00, respectively. The students in concrete level had mean score of 10.29, transitional level had 17.50 and formal level of operation had mean score of 21.00 in computational knowledge.

The treatment of the subjects for eighty weeks using inquiry-based instructions, enhanced their reasoning ability with thirty-seven (37) operating at formal operational level, thirty (30) at transitional level and one hundred ninety-two (192) were found at concrete operational level. The students' achievement mean scores in conceptual knowledge were of 35.02 for concrete level students, 43.63 for transitional level and 51.35 for formal operational level students. The students' mean achievement scores in computational knowledge were 21.13, 24.54 and 26.49 for concrete, transitional and formal levels respectively.

The achievement of the students increased in both conceptual knowledge and computational ability tests as the students moved from concrete cognitive operational level, through transition to formal cognitive operation as indicated in Table 2. These results of students' achievement in conceptual knowledge and computational ability tests based on the cognitive operation levels are pictorially represented in Figure 2.

\section{Conclusion}

The study concluded that:

- Inquiry-based instructions have the capability to stimulate and promote logical reasoning in Chemistry if effectively structured and adequately implemented.

- Students' logical reasoning has influence on students' achievement in conceptual knowledge and computational knowledge in chemistry.

\section{Implication and Recommendation}

The analysis of student's cognitive operations before they were effectively engaged in inquiry instructions indicated that majority of the students was operating in the concrete cognitive operational in Chemistry. One of the factors that are responsible for this level of the students' reasoning is the expository method of teaching which chemistry teacher must do away with for chemistry students to excellently achieve in chemistry. Few weeks of student's engagement in inquiry-based instructions may not necessarily promote formal reasoning attainment in chemistry. This was because high percentage of students was still in concrete operational level after eight weeks of active engagement in inquiry-based instructions. The inquiry- based instructions should be the norm in chemistry lessons for attainment of formal reasoning level in understanding deep knowledge of concepts, abstract thinking and adequate applications of scientific knowledge in solving both personal and societal problems. The students in the PDID and ID that had the opportunity for taking active part in learning processes and involved in the discussions of the processes and products in the learning situation had mean gain scores higher than the TD group with was mainly teacher demonstrations of concepts and their discussions. 
Students' active participation in the learning process made the students to reflect on the learning process and on how to effectively apply the knowledge in solving problems.

Achievement in both quantitative and qualitative is enhanced when student logical thinking skills are promoted through adequate learning methods, enriched learning environment and readiness on the part of the students to participate in the learning process. The acts of analysing, hypothesising, experimenting and drawing inferences in inquirybased instructions stimulate the brain in promoting logical reasoning in the students.

The study recommends the use of inquiry-based instructions that are activity-oriented and problem solving in nature to invoked logical reasoning in enhancing achievement of students in science.

\section{References}

i. Adeoye, I. F. (2016). Effects of inquiry-based learning strategies on senior secondary school students' learning outcomes in chemistry. Unpublished Ph. D Thesis submitted to School of Postgraduate Studies, University of Lagos, Lagos, Nigeria.

ii. Adeoye, I. F., \&Ajeyalemi, D. (2016) Effect of learning in inquiry context on chemistry student's conceptual knowledge at three levels of representation in redox reaction and electrolysis. Lagos Education Review (A journal of studies in Education), 17(1), 133-142.

iii. Adeoye, I. F., \&Ajeyalemi, D. (2018). Effects of inquiry-based learning strategies on chemistry students' conceptions in chemical kinetics and equilibrium. American Journal of Humanities and Social Science Research, 5(10), 57-70.

iv. Adeoye, I. F. (2019). Effects of inquiry-based learning strategies on senior secondary school students' conceptual and computational knowledge in chemistry. International Journal of Social Science Humanities Research. 7(1), 367-376.

v. Adeoye, I. F., \& Agoro, A. A. (2019). The teacher Trainers' Perceptions of the challenges in achieving technological pedagogical content knowledge for teacher education. International Journal of Multidisciplinary and Current Educational Research (IJMCER). 1(5), 32-38.

vi. Adesoji, F. A., \& Omilani, N.A. (2012). A comparison of secondary school's students' levels of conception of qualitative and quantitative inorganic analysis. American Journal of Scientific and Industrial Research, 3(2), 5161.

vii. Anthony, O. O., Shabaan, H. M., \& Nassor, S. M. (2019). A study of performance in Chemistry among lower Secondary Government Schools in Zanzibar. International Journal of Education and Research, 7(2), 221-236.

viii. Bello, A. (2014). Acquisition of the six formal reasoning abilities by students in Kaduna State, Nigeria. International Journal of Education and Research, 2(6), 613-621.

ix. Bhat, M. (2016). The predictive power of reasoning ability on academic achievement. International Journal of Learning, Teaching and Educational Research, 15(1), 79-88.

x. Bird, L. (2010). Logical reasoning ability and students' performance in general chemistry. Journal of Chemical Education,87(5), 541-546.

xi. Ertepmar, H. (1995). The relationship between formal reasoning ability, computer assisted instruction and chemistry achievement. Hacettpe Universites Egitimi Fakultesi Dergisi, 11, 21-24.

xii. Gabel, D. L., \&Bunce, D. M. (1994). Research on problem solving in Chemistry in (D. L. Gabel Ed.) Handbook of Research on Chemistry Teaching and Learning. New York. 301-326.

xiii. Gilbert, J. K., \& Treaquest, D. (2009) Introduction: Macro, sub-micro and symbolic representations and the relationship between them: key models in chemical education. In J. K. Gilbert and Treagust (ed.) Multiple Representations in Chemical Education. The Netherlands: Springer.

xiv. Holme, T.A., Luxford, C. J., \& Brandriet, A. (2015). Defining conceptual understanding in General Chemistry. Journal of Chemical Education, 92 (12), 1477-1483.

xv. Johnstone, A. H. (1991). Why is Science difficult to learn? Things are seldom what they seem. Journal of Computer Assisted Learning, 7, 75-83.

xvi. Kamaruddin, M. I., Abubakar, Z., Surif, J., \&Siew, W. (2008). Relationship between cognitive styles, levels of cognitive thinking and Chemistry achievement among form four science students. http://kajianberasaskansekolah.wordpress.com/2008/05/03relationship-between-cognitive-styleslevel March13, 2013.

xvii. Khoirina, M., Cari, C., \& Sukarmin, S. (2018). Identify students' scientific reasoning ability at senior high school. IOP Conference Series: Journal of Physics. Doi: 10.1088/1742-6596/1097/1/012024.

xviii. Kilic D., \& Saglam, N. (2014). Students' understanding of genetics concepts: the effect of reasoning ability and learning approaches. Journal of Biological Education, 48(2), 63-70.

xix. Kincal, R. Y., \& Yazgan, A. D. (2010). Investigating the formal operational thinking skills of 7thand 8th grade primary school students. Elementary Education online,9 (1), 723-733.

xx. Lawson, A. E. (2009). Development and validation of the classroom test of formal reasoning. Journal of Research in Science Teaching, 15(1), 11-24.

xxi. Lay, Y. K. (2010). The acquisition of logical thinking abilities among rural secondary students of Sabah, Malaysia. Pertanika Journal of Social Science and Humanities,18, 37-51.

xxii. Mari, J. S. (2012). Gender related differences in acquisition of formal reasoning schemata: Pedagogic implication of teaching Chemistry using process-based approaches. International Journal for Cross-Disciplinary Subjects in Education, (IJCDSE), 2, 2, 993-998. 
xxiii. $\quad$ Ngema, M. M. (2016). Factors that cause poor performance in science subjects at Ingwavuma Circuit. Master Degree in Education, University of South Africa.

xxiv. Nnorom, N. R. (2013). The effect of reasoning skills on students' achievement in Biology in Anambra State. International Journal of Scientific \& Engineering Research, 4(12), 2102-2104.

xxv. Ojukwu, M. O. (2016). Perception of students on causes of poor performance in Chemistry in external examinations in Umuahia North Local Government of Abia State. International Journal of Education \& Literacy studies, 4(1), 67-71.

xxvi. Oloyede, O. I. (2012). The relationship between acquisition of science process skills, formal reasoning ability and chemistry achievement. International Journal of Advances in Applied Sciences, 8(1), 1-4.

xxvii. Piaget, J., \& Inhelder, B. (1969). The psychology of the child. New York: Basic Books.

xxviii. Piaget, J. (1983). To understand is to invent. New York: The Viking Press, Inc.

xxix. Piraksa, C., Srisawasdi, N., \& Koul, R. (2014). Effect of gender on students' scientific reasoning: a case study in Thailand. Procedia-Social and Behavioural Sciences, 116, 486-491.

xxx. Santrock, J. W. (2008). A topical approach to life-span development. New York: McGraw-Hill.

xxxi. Taber, K. S. (2019) Conceptual confusion in the chemistry curriculum: exemplifying the problematic nature of representing chemical concepts as target knowledge. Foundation Chemistry. https://doi.org/10.1007/s10698019-09346-3.

xxxii. Yuksel, I. (2019). The effect of research inquiry-based learning on the scientific reasoning skills of prospective science teachers. Journal of Education \& Training Studies, 7(4), 273-280. 